\title{
Listening to junior doctors: exploring morale in a large NHS trust
}

\author{
Authors: Raunak Singh, Joanne Kirtley, Dilesh Lakhani and Sue Carr
}

\section{Aims}

To explore the morale of junior doctors at University Hospitals of Leicester (UHL) NHS Trust, and improve our understanding of the major contributory factors.

\section{Methods}

In November 2017, an online survey was sent to 943 junior doctors working at UHL. We designed this survey to capture a comprehensive picture of junior doctor morale in several domains. Respondents used an ordinal scale of zero (low) to 10 (high) to rate: their overall morale, how valued and supported they felt at work, and how much autonomy they were given. Free-text qualitative comments were sought and responses were thematically analysed to identify common themes. Doctors selected the top five factors that positively affected their morale, from a list of 20 compiled using published literature and local knowledge.

\section{Results}

A total of 402 (42.6\%) junior doctors responded, from a wide selection of departments, specialties, training and non-training grades. The median and range for each of the ordinal ratings is shown in Table 1. Five-hundred and eleven free-text comments were qualitatively analysed by two independent reviewers and eight key themes identified: team working and relationships, feedback, training and education, resources, wellbeing and pastoral support, staffing and workload, senior clinician support and autonomy. The commonest factors that positively affected morale

$\begin{aligned} & \text { Table 1. Ordinal ratings by junior doctors of their } \\ & \text { overall morale, and how valued, supported and } \\ & \text { autonomous they felt }\end{aligned}$
$\begin{aligned} & \text { Overall } \\ & \text { morale }\end{aligned}$
$\begin{array}{lllll}\text { Median } & 6 & 6 & 7 & 7 \\ \text { Range } \quad 0-10 & 0-10 & 1-10 & 0-10\end{array}$

Authors: Department of Clinical Education, University Hospitals of Leicester NHS Trust, Leicester, UK

\begin{tabular}{|c|c|c|}
\hline & Factor & Percentage \\
\hline 1 & Feeling part of a team & 66.4 \\
\hline 2 & Being recognised for good practice & 56.7 \\
\hline 3 & Being able to take regular breaks & 37.3 \\
\hline 4 & $\begin{array}{l}\text { Ease of opportunity to take leave for personal } \\
\text { life and events }\end{array}$ & 33.6 \\
\hline 5 & Having access to a computer or workstation & 31.8 \\
\hline
\end{tabular}

were 'feeling part of a team' (66.4\%) and 'being recognised for good practice' $(56.7 \%$ ) (Table 2 ).

\section{Conclusion}

Our survey has provided insight into junior doctor morale at our trust. Doctors reported that they felt reasonably autonomous and supported but less that their role is valued. Qualitative data demonstrated a number of diverse themes and factors that influence morale. This has initiated a dialogue between junior doctors, senior clinicians and managers, leading to the development of a 'Listening into action' working group, which will utilise the results to improve the working lives of junior doctors at UHL.

\section{Conflict of interest statement}

None declared. 